\title{
NA Kama KaI
}

By Anne Arquit, Kevin Kelly, Philomene Verlaan and Karen Selph

$\mathrm{N}_{\mathrm{A}}$ A KAMA KAI (Hawaiian for sea children) represents the fifty-five graduite students in the Department of Oceanography at the University of Hawaii. The organization was established about eight years ago and currently meets bimonthly during the academic year. Although the social aspect of the organization is not to be overlooked. Na Kama Kai has been increasingly involved with the development and implementation of important departmental decisions over the past several years.

The graduate faculty of the Department of Oceanography often solicit input from $\mathrm{Na}$ Kama Kai on issues ranging from personnel matters tocurriculum. Na Kama Kai elects a student each year to serve as the graduate student representative at faculty meetings.

This allows students to bring items of interest to the attention of the faculty and also keeps students up-to-date on faculty concerns and the development of departmental policies. The dialog has been quite satisfactory.

For example, at the urging of Na Kama Kai, the faculty have cooperated in the expansion of brown-bag seminars, which give students the opportunity to present and discuss their research with peers in an informal setting. Na Kama Kai also selects students to serve on departmental committees dealing with space allocation. curriculum, search committees for new faculty. etc. Na Kama Kai interviews all new fac-

Anne Arquit, Kevin Kelly, Philomene Verlaat and Karen Selph, Lniversity of Hawai at Manoa, Department of Oceanography, Division of Natural Sciences, 1000 Pope Road. Honolulu, HI 96822. ulty candidates and transmits a consensus view of student comments to the graduate faculty for their consideration. This constructive interaction between students and faculty is strongly encouraged by our present department chairman. who has made it a particular point to ensure student representation on all departmental committees.

The oceanography faculty realize that having a strong graduate student organization like Na Kama Kai benefits the department as a whole. Graduate students in oceanography have been among the most active participants in the University"s Graduate Student Organization, the "governing" body of the 4,100 classified graduate students at the University of Hawaii. One is currently completing a term as president of the organization. Because Na Kama Kai has been active in campus-wide affairs. the interests of the Oceanography Department have been well represented on a number of key unjersity committees, including those dealing with priorities for the university budget and the selection of deans of both the Graduate Division and the new School of Ocean \& Earth Science and Technology (SOEST). Na Kama Kai has voiced its collective opinion to the faculty. the university administration and the state legislature.

$\mathrm{Na}$ Kama Kai serves several other important functions for the department. Each semester, entering students are contacted and arrangements for their arrival in Hawaii are made, including temporary housing with current students. which often serves as a useful introduction to Hawaiian culture and our distinctly "island" lifestyle.
Na Kama Kai also assumes responsibility for planning and overseeing the New Student Party each fall.

This event involves all staff, faculty and students in the department and is intended to introduce new students to their colleagues, as well as to allow everyone to catch up on the dynamic research interests of oceanography faculty.

Intramural sports are also organized through Na Kama Kai. Although the Shooting Seamen have never had a win-loss record over .500 in any sport, postgame beer drinking usually numbs any thought of failure.

With the establishment of the SOEST in 1988, there is potential for greater interaction between Na Kama Kai and the graduate students of the Departments of Geology \& Geophysics, Meteorology. and Ocean Engineering, as well as the Hawaii Institutes of Geophysics (HIG) and Marine Biology (HIMB). Geology students have maintained an extremely successtul T.G.I.F. program, with the assistance of oceanography students. Each Friday, faculty and graduate students flock to the grassy courtyard that separates the building where "ocean scientists" work from that of the "earth scientists." The substantial attendance at T.G.I.F. indicates how artificial this separation is becoming. We believe the oceanography students at the University of Hawaii. through their organization of $\mathrm{Na}$ Kama Kai. have found an effective approach to encourage the type of interdisciplinary and institutional interaction that is needed to address global issues in the $1990 \mathrm{~s}$ and beyond. $\square$ 